\title{
Dying and the Social Responsibility of Institutions
}

Roger A. Lohmann

West Virginia University, roger.lohmann@mail.wvu.edu

Follow this and additional works at: https://researchrepository.wvu.edu/faculty_publications

Part of the Social Policy Commons, Social Welfare Commons, and the Social Work Commons

\section{Digital Commons Citation}

Lohmann, Roger A., "Dying and the Social Responsibility of Institutions" (1977). Faculty Scholarship. 1160. https://researchrepository.wvu.edu/faculty_publications/1160

This Article is brought to you for free and open access by The Research Repository @ WVU. It has been accepted for inclusion in Faculty Scholarship by an authorized administrator of The Research Repository @ WVU. For more information, please contact ian.harmon@mail.wvu.edu. 


\section{Dying and the Social Responsibility of Institutions ${ }^{1}$}

Roger A. Lohmann²

Contemporary American society has established a comfortable reliance upon a large network of total and quasi-total institutions for dealing with certain life threatening events and socially disruptive conditions As a consequence these institutions have become primary locales for dying. It is the principal argument of this paper that although a large proportion of all deaths now occur in institutions, they are generally harsh and unsympathetic in their handling of dying, and particularly insensitive to the social and psychological needs of surviving significant others in the period immediately following a death. It is suggested that along with accepting the responsibility to care for terminally ill patients, such institutions should also accept responsibility for aiding survivors following a patient's death.

\section{Introduction}

One of the distinctive characteristics of modern human services has been the rationalization of helping. ${ }^{3}$ Acts of altruism and charity formerly accepted as religious responsibilities or familial duties have become in urban industrial society the substance of a number of professions and a welter of service organizations. Dying is one of those events and processes which has come under such rationalization with the result that an estimated one half of all deaths in the United States occur in hospitals or long-term care institutions. This rationalization of death has been at best incomplete and a number of situational problems arise regularly.

Several recent studies have made the point that physicians, social workers, nurses, psychologists and other professions who work in such settings are frequently unwilling or unable to deal satisfactorily with the social and emotional dimensions of death (Glaser \& Strauss, 1967; Kubler-Ross, 1969). An equally significant but often overlooked point is that the official stance of such institutions toward death - as reflected in their policy statements, rules and regulations, and public pronouncements - is often also one of denial. Administrators, board members, supervisors, public information officers and others often strive consciously to overcome the image of long-term care institutions as places to die.

\footnotetext{
${ }^{1}$ Special thanks are due to Elizabeth Rasmussen and Carl Gaddis for their research assistance on this paper. An earlier draft, co-authored with Carl Gaddis, was prepared for a conference on Social Work with the Dying and Long Term Care Institutions, April, 1975. The conference was sponsored by the Foundation for Thanatology, New York, which subsequently published the paper as "The Social Work Contract and Survivorship Services."

${ }^{2}$ Author's preprint. At the time this paper was published the author was an Assistant Professor at the University of Tennessee, Knoxville.

${ }^{3}$ Author's note: This article was published just before Cicely Saunders' introduction of the idea of modern hospice services to the U.S. and the idea of hospice became widely accepted. Modern hospices routinely provide some of the kinds of survivor services called for in this article and refer clients to other available services. Likewise, it was in the very early phases of research on the role of familial and other "support systems" so the discussion may appear quite naïve with the benefit of hindsight.
} 
The consequences of this for the dying resident are fairly clear. Death often occurs in inhospitable, insensitive and anxiety-prone environments. What is less clear is the impact of dying in these circumstances upon the survivors - family members, friends and significant others for whom life continues. In far too many instances the death of a resident may simply mean the cessation of any institutional commitment or services to family members. Unfortunately, even tragically, this cessation of service comes precisely at the point when such service might be highly valuable to the survivors. There is at present extensive research support - including that reviewed below - for the conclusion that survivorship is a social status characterized by a broad range of personal troubles of a somatic, psychic and social nature. Under the circumstances a far more human and sensible approach by large institutions would be a realistic recognition of the inevitability of dying and of the needs of survivors created by the occasion of death. Because survivorship is, by nature, a volatile transitional status which ordinarily loses the burden of its significance in a relatively brief period, services to survivors would ordinarily be of a temporary, transitional nature. In the remainder of this paper I shall attempt to build a case for the needs of survivors and the responsibility of institutions to deal with those needs. This includes examination of current research on the nature and characteristics of survivorship and construction of a framework within which to view survivorship services.

\section{Survivorship}

There are always at least two parties to a death, according to Toynbee: The person who dies and the survivors who are bereaved (Toynbee, 1968). Survival following the death of any significant other is a profoundly paradoxical situation: In some respects, nothing has changed for the survivor, large aspects of the life experience remain intact. One may still go to work or to school and carry on other daily routines. And yet, a death also introduces an irrevocable, final and irreversible change in the nature of man's social and personal existence. However, the meaning of this change for the survivor is, itself, subject to change over time. In a physiological sense, one is the survivor permanently from that death to one's own death.

In a social sense, however, surviving represents a particular configuration of meanings and behavior whose significance ordinarily becomes less all-encompassing and pervasive as grief work proceeds and eventually assumes its "proper place" in the overall life history of the survivors. Many of the most significant social aspects of the career of survival can be denoted by arbitrarily dividing this period into four principle periods: the pre-funeral period, in which survivors are faced with the awesome emotional task of accepting the reality of the death that has occurred; the ceremonial and ritualistic period of the funeral which follows, during which the survivors must accept the reality of what has occurred and say farewell to the deceased; the post-funeral period of mourning, which is ordinarily the longest and most challenging time for survivors; and reemergence in which survivors indicate 
by their actions at least a modicum of acceptance and willingness to resume normal living.

\section{Research on Survivors}

The circumstance of surviving and its effects upon persons have been a subject of considerable research interest in recent years. Findings from studies in Great Britain and the United States appear to be in substantial agreement on a number of general findings regarding survivorship.

One finding of considerable interest involves the duration of grieving and active survivorship. While custom, tradition, and social institutions have often placed specific time limits upon survivorship for widows (e.g., the traditional practice of wearing black for a year of official mourning), data collected by Helena Z. Lopata's study of Widowhood in an American City suggest large variation in the length of actual mourning (see Table 1).

Table 1

Length of Time of Grief After the Death of the Husband

\begin{tabular}{|l|c|c|}
\hline \multicolumn{1}{|c|}{ Length of Time } & Number of Cases & Percentage \\
\hline Less Than One Month & 3 & 1.2 \\
\hline 1-5 Months & 14 & 5.7 \\
\hline 6-12 Months & 29 & 11.8 \\
\hline 12 Months & 73 & 29.7 \\
\hline 13-23 Months & 6 & 2.4 \\
\hline 24 Months & 39 & 15.9 \\
\hline 25 Months & 31 & 12.6 \\
\hline Always, Never Got Over It & 50 & 20.4 \\
\hline No Answer & 56 & $22.8^{*}$ \\
\hline
\end{tabular}

*Not included in percentage base $($ Sample size $=245)$

The distinction between the emotional responses of grieving and the behavior patterns of survivorship should remind us at this point that this table does not necessarily identify the curvive of surviving for these widows. It does not mean, for example, that they can be expected to resume mornal social life immediately upon the resolution of grief. That there is a connection between the emotional state of grief and the social status of surviving, however, can be seen in the following descriptions of common grief reactions: 
Common to all persons in acute grief) is the following syndrome: sensations of somatic distress occurring in waves lasing from twenty minutes to an hour at a time, a feeling of tightness in the throat, choking with shortness of breath, need for sighing, and an empty feeling in the abdomen, lack of muscular power, and an intense subjective distress described as tensions or mental pain. The patient soon learns that these waves of discomfort can be precipitated by visits, by mentioning the deceased, and by receiving sympathy. There is a tendancy to avoid the syndrome at any cost, to refuse visits lest they should precipitate the reaction, and to keep deliberately from thought all references to the deceased. (Lindeman, 1944)

The typical reaction to bereavement begins with a period of numbness, followed by wave-like attacks of yearning and distress with autonomic disturbance, which are aggrevated by reminders of the deceased. Between attacks, the bereaved person is depressed and apathetic, with a sense of futility. Associated symptoms are insomnia, anorexia, restlessness, irritability with occasional outbursts of anger directed against others or the self and preoccupation with thoughts of the deceased. The dead person is commonly felt to be present, and there is a tendency to think of him as if he were still alive and to idealize his memory (Parkes, 1965)

Leaving aside slight differences in interpretation it should be readily apparent that the persons described are not likely to be highly social, nor in many instances to be highly valued for their social participation or skills. This latter point is a critical one in a society as dependent upon non-primary social relationships as ours. Aloneness and isolation are relatively common experience for many survivors in urban, industrial society, and such isolation probably coincides with, and exacerbates a number of other problems for survivors. Existing research suggests five principal conclusions which are of direct interest here:

1. Increased mortality rates during bereavement have been found among all survivors (spouses, siblings and children).

2. No evidence has been found to support the conclusion that significant increases in major illnesses occur among the bereaved.

3. Evidence is plentiful that deterioration in general health levels and marked increases in psychosomatic complaints are common. 
4. There is also evidence to suggest marked increases in what might be termed psychiatric morbidity or the existence of psychiatrically significant behavior.

5. There is evidence that many survivors seek out professional help for grief-related problems

\section{Increased Mortality and Morbidity Among Survivors}

C. Murray Parkes found that mortality rates among widowers over age 55 increased by over one third in the six months following their spouses' death's (Parkes, 1964A). It was also determined in a follow-up study that this was a temporary phenomenon; mortality rates for this population return to normal within a year of bereavement (Parkes, Benjamin and Fitzgerald, 1969). Rees and Lutkins found similar statistically significant differences in mortality rates among surviving parents, children and siblings, and determined further that such differences in mortality rates were more pronounced among males (in all categories than among females (Rees \& Lutkins, 1967). In another study Young, Benjamin and Wallis found increases in the death rate of widowers over 54 years old of nearly 40 percent during the first six months of bereavement followed by a rapid return to normal rates (Young, Benjamin \& Wallis, 1963).

In the study already cited, Rees and Lutkins (1967) also determined a relationship between the place of the initial death and the later mortality of survivors which is of central importance to this paper. They found that the increased risk of dying within one year of the initial bereavement was nearly twice as high if the initial death occurred in an institution than if it occurred at home. Although they did not probe the meaning of this, several possible explanations come to mind: 1) At least some institutional deaths could be due to infectious or contagious diseases spread to these survivor-cum decedents. 2) Deaths in institutions may occur over extended periods of time, thus, inflicting more mental and physical trauma upon individual survivors and increasing their risk of mortality; or 3) It is at least possible that death in an institution - which is, after all, a relatively new phenomenon in American life - is disruptive of "natural" communal and familial patterns for the handling of grief in ways which are not yet presently understood. The profound emotional experience of bereavement is hardly an ideal match for the narrow rationalism of the modern corporate or bureaucratic care-giving institution. Thus, grief and institutions may interact in unspecified ways to produce increased mortality.

The previously mentioned follow-up study by Parkes, Benjamin and Fitgerald published in 1969 also sheds some intriguing - if ambiguous - light upon this question. Investigation of the causes of death listed on the death certificates of those in their 1963 study revealed that three-fourths of the increase in death rates was attributable to "heart disease." Of all the physical maladies of man, perhaps none is more clearly linked to our social existence and emotional states than heart disease. 
But other studies have also suggested that survivors may be less inclined to contact major new diseases than to suffer general declines in health levels and acceleration of previous conditions. In three studies of widows who were married to men aged 45 to 60 at the time of death, Maddison and colleagues found significant decreases in self-reported health levels, but no significant increases in the prevalence or severity of major diagnosed illness categories (Maddison, 1968; Maddison \& Viola, 1968; Maddison \& Walker, 1967). What they did find were significantly higher reported incidence of headaches, dizziness, fainting spells, dermatological problems, mild gastro-intestinal disturbances varying from indigestion to vomiting and anorexia, menorrhagia, chest pains and frequent infections, as well as increases in smoking, alcohol and drug intake (especially sedatives). Marked deterioration in health was shown by 21.2 percent of the sample studied, while a similar control group of women whose spouses had not died slowed only 7.2 percent with any marked health deterioration during the same period. While we can tentatively accept this finding, Parkes later cautioned that we do not yet have anything like a complete understanding of the relationship between health and survivorship (Parkes, 1974).

\section{Deterioration of Emotional Health}

Recent research shows that death affects the emotional health of the survivor most seriously when the person bereaved wa a spounse. Parkes found a six times greater probability of being admitted to a psychiatric clinic in the period of being admitted to a psychiatric clinic in the period immediately following the death of a spouse, but no increased probablility following the death of other relatives (parents, child, sibling) (Parkes, 1964A; Parkes, 1964B; Parkes, 1964C). This would also suggest that widows may be the group most in need of the type of survivorship services proposed here. Among the study and control groups of Maddison and Viola cited above, a significan increase in general nervousness, depression, fears of "nervous breakdown", feelings of panic, persistent fears, nightmares, insomnia and trembling were reported. Bock concluded after a study of Florida widows that "the widowed, especially males, are more likely to commit suicide than the married. (Bock, 1972). Stein and Susser also found abnormally large proportions of survivors among persons entering psychiatric care for the first time (Stein \& Susser, 1969).

\section{Social Integration and Disengagement}

Bock, Stein \& Susser, Silverman, Philblad \& Adams, and Berardo all found the widowed to be less involved in social life, to demonstrate greater role ambiguity and to have fewer social interactions and fewer social ooutlets along with the higher incidence of mental disorders cited above (Bock, 1972; Stein \& Susser, 1969; Silverman, 1972; Philblad \& Adams, 1972; Berardo, 1970). In general, all of these studies appear to support Silverman's conclusion that:

In the United States, a person's mourning is supposed to be of short duration and to end before the widow or 
widower understands what the new role means or how it will affect his (or her) life. This pressure to not express one's bereavement can in fact only intensify the grief (Silverman, 1972).

This conclusion is stressed repeatedly in contemporary studies of grieving. Contemporary social institutions simply provide inadequate support of grief work and little effective socialization to the experiences of post-survival living. It seems abundantly clear, therefore that attention to these considerations should be the keystone of efforts to aid survivors.

\section{Help-Seeking Behavior}

It is very unlikely that the need for such services is currently unrecognized among survivors. Studies in both Britain and the United States have shown a pattern of help-seeking behavior ion the part of survivors, although some differences in who survivors turn to have been noted. British survivors tend to seek assistance with emotional problems of grief from primarily physicians and clergymen, while American survivors may also seek assistance from psychiatrists and social workers. The British sample also showed marked increases in physician office visits, but no increases in hospitalization, while the American sample showed no evidence of increased office visit, but a four-times-higher than normal rate of hospitalization during the first year following bereavement (Parkes, 1970A; Parkes \& Brown, 1972; Parkes, 1970B).

\section{Survivor Services}

Few, if any, survivors are able to handle the emotional and social aspects of surviving without any assistance. The question naturally arises as to the social arrangement of such assistance. In many societies, including large segments of American society, dying is essentially a family matter and other family members continue to provide aid and comfort to survivors following bereavement - often in a kind of status ordering based upon assessments of the closeness of various survivors to the deceased. ("My sister is much closer to Aunt Joyce than I am; but I'll be there if she needs me." Etc.) Perhaps most important in determining such closeness is the degree of reciprocity implied by the giving and receiving of such aid: "I know she'd be there for me if I needed her." Yet for some there are no such supporters; They find themselves with no one to turn to.

It is not my intention in this paper to find fault with familial, peer group or neighborhood support systems. When such support occurs, it would appear to provide exactly the kind of practical and emotional support needed by survivors. I wish merely to observe, however, that the circumstances of urban-industrial life make non-occurrences of such spontaneous mutual aid highly likely in a number of instances. In the case of widows without children living in urban areas or great 
distances (physical or social) from other relations, or of single women or men living along (including the homeless and those with substance abuse problems) such supports are likely to be weak or nonexistent. The primary question which arises iin that case is whether it is possible to create any arrangements which provide at least partial replacement for the non-existent family support during this period of bereavement?

It is my intention in the remainder of this paper to sketch some of the requirements for such a "helping service" and to make the case for establishment of such services as a kind of aftercare following deaths which occur in long term care institutions. Certainly, such services are not needed for everyone, but for those without other means of support to turn to they should be available as an option.

It should be noted also that a number of social workers and nurses in hisotals and long-term care institutions with whom I have discussed this idea, say they already attempt to provide such services where appropriate - and are often frustrated in their efforts by the lack of official recognition and sanction. "That's not our job, my supervisor told me," one said.

The argument for survivorship service has also been presented in part by Schneiderman's call for "postvention," although his perspective is principally directed at the clinical aspects of the question, while I am more concerned about the matter as an organizational policy concern (Schneiderman, 1976).

In the following paragraphs some of the basic questions of the organization of such services will be taken up. An initial question of great importance is how long such services should last? In general, to be maximally useful such services should roughly parallel the period of grief, gradually being withdrawn as the widow reemerges into a more normal social existence. In some instances, this may be needed for one month, and in other instances for 18 months or longer, but it seems likely that the average might turn out to be around six months (See Table 1).

The essential questions appears to be what type of assistance such a service would provide to survivors? In general, this would vary somewhat depending upon the period of survivorship involved. In the numbness of the pre-funeral period, aid with daily activities transportation, meal preparation, funeral arrangements, notifications to distant relations, and a myriad of other tasks might be appropriate at this point. Attention may also need to be given at this point to assist with initiating grief work. Throughout all stages of survivorship, the heaviest burden of responsibility for such services would be for assistance with grieving. "Postventive efforts are not limited to this initial stage of shock but are more often directed to the long haul" (Schneiderman, 1976). Also during this period, special attention may be needed to referrals to specialized legal, psychiatric or medical assistance.

Particularly in the latter stages of grieving such services might be directed at problems of "reemergence." A widow may find it necessary to move, find a job, or in other ways make the kind of changes at which she is inexperience. Two aspects of the reemergence problem may be particularly useful points for service. One of these 
involves teaching new skills for which survivors were formerly dependent upon the deceased, whether paying bills, operating equipment or vehicles, paying taxes, operating a household, or other similar tasks. The other of these challenges is assistance with the establishment of new primary group relations (e.g, new confidants), an arrangement that Lopata, Clark \& Anderson and others find essential to well-being (Lopata, 1973; Clark \& Anderson, 1967). Such survivorship services should also have arrangements incorporated for backup referrals to a variety of medical, psychological and legal expertise since any of the broad range of practical problems experienced by survivors can, in some instances, be serious enough to require more intensive or expert assistance than is envisioned for this particular service. Schneiderman, for example, recommends that all survivors should have complete physical examinations. Some may also benefit from more intensive psychotherapy or counseling (Schneiderman, 1976).

A third important question involves the organization and delivery of such survivorship services Several possibilities exist here for such services. There are a number of existing agencies available in most communities to which such services could readily be appended - departments of public welfare social service units, for example, or family service associations, mental health clinics and associations, aging councils and other, similar agencies. The difficulty with all of these services, however, is the gap between the location and circumstances of dying and the availability of survivorship services. Large numbers of people do not die in the public welfare office, and if such a death does occur it is treated as highly unusual. Further, survivors are hardly ideal candidates for the kind of phone calling, appointments, transportation issues and reconnaissance efforts which often accompany the initial visit to these service agencies. Thus, linking survivorship services to such community service agencies would probably insure that a major portion of those in need went unaided. A far more satisfactory arrangement would be to base these services closer to the circumstances of dying.

Two possibilities, in particular, stand out. One would be to attch survivorship service units to Medicaid-processing units in Departments of Public Welfare - an arrangement which has multiple drawbacks. Seemingly, a more satisfactory arrangement would be to incorporate survivorship services as part of the service array of long term care institutions themselves. In addition to the obvious continuities this would involve, such an arrangement would seemingly also provide certain additional advantages: It could, for example, be a means of attempting to dull the institutional insensitivities so often displayed at the time of a death.

At present the significant others who immediately become survivors upon the occasion of a death have very tenuous ties to that institution: Seemingly their only ties are (or were) through the patient and these are often terminated at that death, sometimes in heartless and cruel ways. Immediately following the death, for example, death-bed survivors may be unceremoniously escorted from the room into a hallway or public lounge so the staff may get on with the work of preparing the body, or even clearing the room. Whether the survivors leave the building 
completely or stay in the lounge is ordinarily a matter of indifference to the staff of the institution so long as removal of the deceased and his/her effects proceeds on schedule. Such insensitivity is hardly warranted and ideally institution-sponsored survivorship services would be available at that point to at least humanize the initial shock of death. If the dying has been long and protracted, survivors could already have been engaged by survivorship staff by the time death occurs. In any case, such an arrangement would seem preferable to survivors being unceremoniously dumped on the stoop, as so frequently happens.

A second, equally compelling, reason for institutions to develop aftercare services for survivors is the means they offer to legitimate grief work among staff. Long term care, by its nature, sets up what Schneiderman calls "dire wards" in which dying patients are often around long enough to form personal relations with staff, who are often enough survivors themselves in very real (if unrecognized) sense. In fact, in at least some cases, the reported cruelties and insensitivities might be explained as grief-related reactions by institution staff. Could such staff members - whose grief may be comparable to that of some relatives in acuity - serve to provide the kinds of services described above to the more acutely aggrieved for a period of time? Wouldn't such an arrangement allow for more meaningful and humane termination of the staff-patient relationship and its attendant ramifications than the "contract closure" so commonly practiced now? The answers to all of these questions appear to be yes. In all likelihood, survivorship services offered as part of the overall service package of a long-term care institution would all for better institutional handling of dying all around, as well as providing more effective means of meeting the needs of survivors.

The key question, perhaps, is how to finance such services. This question, of course will require extensive investigation. However, just briefly, several possibilities appear feasible: One would be to establish a kind of internally managed insurance or capitation scheme, wherein a certain (probably quite small) portion of resident fees could be set aside in a reserve fund regularly for each patient as "insurance" against dying - and creating survivors who must be cared for. The benefit of such insurance would be in the form of survivor services supported by the insurance fund. Other, more conventional, means to support such services would be through more traditional sources like fees or grant income. In any event, the use of line staff to accept temporary duty working with survivors would probably also be fairly economical since such survivor services would only take extensive time and effort for a very short period following the death.

\section{Conclusion}

This paper is an attempt to outline the need for, and the possibilities of organized survivorship services operating from long term care institutions. Research on survivors seems to indicate the need for a considerable amount of assistance during the periods of acute grief, and for many in urban, industrial society, the familial and other supports which are sources of such aid are lacking. 
Therefore, it is suggested, the need exists to extend such services to survivors. Providing such services as a form of aftercare in long term care institutions, it was suggested could be beneficial not only for survivors, but also in facilitating the recognition of death, and grief work among staff members of such institutions. 


\section{References}

Berardo, F. M. (1968). Widowhood status in the U.S.: Perspective on a neglected aspect of the family life cycle. Family Coordinator, 17, 191-203.

Berardo, F. M. (1970). Survivorship and social isolation: The case of the aged widower. Family Coordinator, 19, 11-25.

Bock, W. E. (1972). Aging and suicide: The significance of marital kinship and alternative relations. Family Coordinator, 21(1), 71-79.

Clark, M., \& Anderson, B. (1967). Aging and Mental Disorders in San Francisco. San Francisco: Jossey-Bass.

Glaser, B. G., \& Strauss, A. L. (1965). Awareness of dying. Chicago,: Aldine Pub. Co.

Kubler-Ross, E. (1969). On death and dying. New York: Macmillan.

Lindemann, E. (1944). Symptomatology and management of acute grief. American Journal of Psychiatry, 101, 141-148.

Lopata, H. Z. (1973). Widowhood in an American city. Cambridge, Mass.: Schenkman Pub. Co.; distributed by General Learning Press [Morristown, N.J.

Maddison, D., \& Viola, A. (1968). The relevance of conjugal bereavement for preventative psychiatry. British Journal of Medical Psychology, 41, 223-233.

Maddison, D., \& Walker, W. (1967). Factors affecting the outcome of conjugal bereavement. British Journal of Psychiatry, 11, 1057-1067.

Maddison, D., \& Walker, W. (1968). The health of widows in the year following bereavement. Journal of Psychosomatic Research, 12, 297-306.

Parkes, C. M. (1964). Grief as an illness. New Society, pp. 11-12.

Parkes, C. M. (1964). Recent bereavement as a cause of mental illness. British Journal of Psychiatry, 110, 198-204.

Parkes, C. M. (1964). The effects of bereavement on physical and mental health: A case study of the case records of widows. British Medical Journal, 110, 198.

Parkes, C. M. (1965). Bereavement and mental illness: Part II. A Classification of Bereavement reactions. British Journal of Medical Psychology, 38, 13-26.

Parkes, C. M. (1970). The first year of bereavement: A longitudinal study of the reaction of London widows to the death of their husbands. Psychiatry, 33, 444.

Parkes, C. M. (1970). The psychosomatic effects of bereavement. In O. W. Hill (Ed.), Modern Trends in Psychosomatic Medicine. London: Butterworth.

Parkes, C. M. G., I. O. (1974). First Year of Bereavement. New York: John Wiley \& Sons. 
Parkes, C. M., \& Benjamin, B. (1965). Broken heart: A statistical study of increased mortality among widowers. British Medical Journal, 38, 13-26.

Parkes, C. M., \& Brown, R. J. (1972). Health After Bereavement: A Controlled Study of Young Boston Widows and Widowers. Psychosomatic Medicine, 34, 449-461.

Philblad, C. T., \& Adams, D. L. (1972). Widowhood, social participation and life satisfaction. Aging and Human Development, 3, 323-330.

Rees, W. D., \& Lutkins, S. G. (1967). The mortality of bereavement. British Medical Journal, 4, 13-16.

Schneiderman, E. S. Postvention and the survivor-victim. In In Death: Current Perspectives. Palo Alto: Mayfield.

Silverman, P. (1972). Widowhood and preventative intervention. Family Coordinator, 21, 95-102.

Stein, Z., \& Susser, N. W. (1969). Widowhood and mental illness. British Journal of Preventative and Social Medicine, 23, 106.

Toynbee, A. (1969). Man's concern with death. St. Louis: McGraw-Hill.

Young, M., Benjamin, B., \& Wallis, C. (1963). Mortality of widowers. Lancet, 2, 454. 